This item was submitted to Loughborough's Research Repository by the author.

Items in Figshare are protected by copyright, with all rights reserved, unless otherwise indicated.

\title{
Design-oriented approach to determine FRC constitutive law parameters considering the size effect
}

PLEASE CITE THE PUBLISHED VERSION

https://doi.org/10.1016/j.compstruct.2020.112036

PUBLISHER

Elsevier BV

VERSION

AM (Accepted Manuscript)

\section{PUBLISHER STATEMENT}

This paper was accepted for publication in the journal Composite Structures and the definitive published version is available at https://doi.org/10.1016/j.compstruct.2020.112036

\section{LICENCE}

CC BY-NC-ND 4.0

\section{REPOSITORY RECORD}

Galeote, Eduardo, Ana Blanco-Alvarez, and Albert de la Fuente. 2020. "Design-oriented Approach to Determine FRC Constitutive Law Parameters Considering the Size Effect”. figshare.

https://hdl.handle.net/2134/12103443.v1. 


\section{Design-oriented approach to determine FRC constitutive law parameters}

\section{2 considering the size effect}

3 Eduardo Galeote $^{\mathrm{a}, *}$, Ana Blanco ${ }^{\mathrm{b}}$, Albert de la Fuente ${ }^{\mathrm{a}}$

4

5 a Department of Civil and Environmental Engineering, Universitat Politècnica de

6 Catalunya, Jordi Girona 1-3, 08034 Barcelona, Spain

7 b School of Architecture, Building and Civil Engineering, Loughborough University,

8 Loughborough, Leicestershire LE11 3TU, United Kingdom

$9 *$ Corresponding author: Eduardo Galeote. Department of Civil and Environmental

10 Engineering, Universitat Politècnica de Catalunya, Jordi Girona 1-3, 08034 Barcelona,

11 Spain. Email address: eduardo.galeote@upc.edu

13 Abstract

14 Tensile strength constitutive laws for fibre reinforced concrete (FRC) are commonly

15 defined through the parameters of flexural tests conducted on standard prismatic

16 specimens. However, there are no specific criteria to determine such parameters using

17 small specimens that could simplify the testing procedure and provide more representative results of slender structural FRC elements. In this line, the influence of size effect becomes an issue particularly relevant during the characterisation stage given that the residual strength decreases while increasing the size of the element. The objective of this document is to propose a methodology to obtain the parameters of the constitutive law using small specimens. For this, FRC residual strength was determined through three-point bending tests on prismatic notched beams of 40x40x160, 
100x100x400 and 150x150x600 mm. An analytical model based on sectional analyses aimed at reproducing the flexural strength of FRC was used to assess the results of the alternative methodology to determine the parameters for the constitutive law. The results show that an approach based on the rotation instead of the crack opening as the reference parameter to estimate the stresses for the constitutive law leads to results less influenced by the size effect when designing small elements.

\section{INTRODUCTION}

Size effect has been an issue extensively studied and reported in the literature, with different theoretical approaches arising to explain such effect. According to previous investigations, using specimens of different dimensions to determine the flexural response of fibre reinforced concrete (FRC) has several implications regarding size effect that may influence the nominal strength. While some studies [1] conclude that the size effect on the flexural strength is almost negligible, other researchers [2] state that the size effect cannot be disregarded. This issue was addressed in additional investigations [3] by analysing the residual strength of different sized concrete specimens with and without fibres and concluded that increasing the size of the specimen leads to a reduction in the strength [4].

Despite the evident presence of size effect on concrete, most of the design codes and standards currently into effect still assume that the behaviour of concrete follows the classical theories of elasticity and plasticity [5]. In this regard, it is broadly accepted that both tensile and flexural strength capacities of concrete are not affected by the size effect at the structural design level. In the case of FRC, the fact of being a relatively new material for design purposes has also led to generally assume there is no size effect. 
47 Among the existing codes and guidelines with specific FRC constitutive laws, only the German code (DBV) and the RILEM recommendations [6] account for the size effect by introducing a correction factor to reduce the strength as the size of the specimen increases [7]. Unlike the DBV and the RILEM specifications, the constitutive model for FRC of the fib Model Code 2010 (MC2010) [8] assumes an equivalent residual strength between the standard beam and the structural element. In this line, it has been reported [9] that the direct application of constitutive models on real-scale elements without considering the size effect may lead to an unsafe design given the influence of the geometry differences and the variations of the fibre distribution and orientation depending on the size of the element. For this, the MC2010 suggests considering an orientation factor $(K)$ to take into account the favourable or unfavourable effect of the fibres $[10,11]$.

Constitutive models for the design of FRC real-scale elements are usually based on the results of standard prismatic beams tested under a three-point bending configuration. In this regard, this study aims to analyse whether small specimens may be used to determine the post-cracking parameters of FRC and which assumptions need to be taken for this purpose of guaranteeing the required reliability of the resulting design parameters. Hence, the cracking mechanism is analysed in detail to propose an approach based on replacing the crack mouth opening displacement (CMOD) for the rotation of the specimen as the reference parameter to determine the residual strength of FRC. The method consists of an inverse analysis to analytically compute the FRC flexural performance, which allows obtaining the load-deflection or load-crack opening curves by using the constitutive law of the MC2010. The analytical results are consequently compared to experimental results conducted on prismatic beams of different sizes 
$71(40 \times 40 \times 160,100 \times 100 \times 400$ and $150 \times 150 \times 600 \mathrm{~mm})$ to determine which reference parameter-CMOD or rotation-presents the closest results to the experimental curves.

Finally, an alternative approach to assess the constitutive law for FRC using small nonstandard specimens is proposed based on the obtained results. This approach can lead to simplify the testing procedure while providing more representative results for thin or slab-shaped FRC elements, which are commonly subjected to a greater influence of the preferential fibre orientation that takes place $[12,13]$.

\section{ANALYTICAL ASSESSMENT OF THE POST-CRACKING STRENGTH}

\subsection{Constitutive law for FRC}

Different constitutive models in varying degrees of complexity and accuracy may be found in the literature and national or international codes for FRC [7] and even for ultrahigh performance fibre reinforced concrete [14]. The main particularity of the stressstrain tensile law of the MC2010 for FRC with respect to other codes is that it can distinguish among three cases of softening and hardening behaviour (Fig. 1). The branches describing the strain-softening or strain-hardening post-cracking performance are defined by the stress and the strain at both Service and Ultimate Limit State (SLS and ULS). The stress parameters are calculated through the results of the three-point bending test (3PBT) conducted according to the standard EN 14651:2007 [15]. Based on the specifications of the MC2010, the strain may be obtained as the ratio between the crack opening and the characteristic length $\left(\varepsilon=w / l_{c s}\right)$. At ULS, the MC2010 limits the strain $\left(\varepsilon_{U L S}\right)$ to $10 \%$ in hardening and $20 \%$ in softening. 


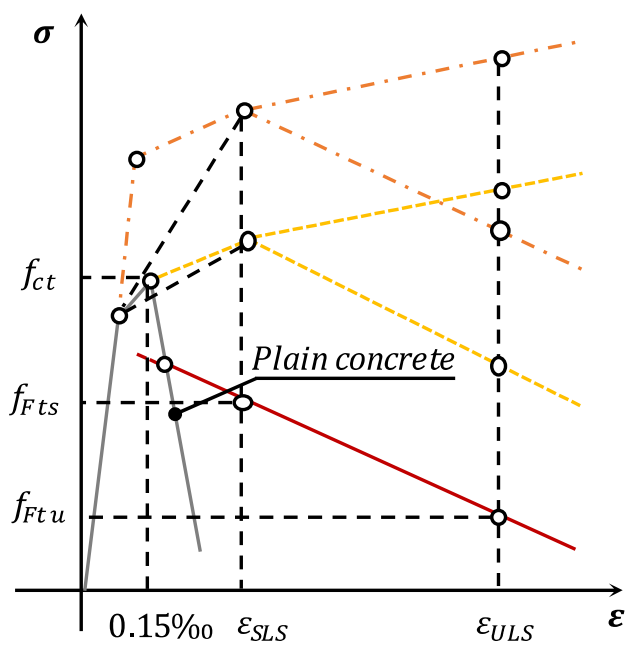

Figure 1. Constitutive law for FRC in tension [8].

94 The characteristic length $\left(l_{c S}\right)$ is an indicator of the crack spacing used in calculations

95 whose value is influenced by several factors such as the type or content of fibres, the

96 matrix strength and the load level, among others [16]. Studies in the literature reveal

97 that there is not a clear consensus to specify $l_{c s}$ and researchers use different criteria to determine its value [16]. However, the MC2010 suggests considering $l_{c s}$ to be equal to the depth of the structural element to be designed, a criteria that has been used and 100 validated by several authors $[17,18]$.

\subsection{Alternative approach to calculate the constitutive law for FRC}

The 3PBT provides three strength values $\left(f_{L O P}, f_{R 1}, f_{R 3}\right)$ which are used to calculate the parameters of the constitutive law $f_{c t}, f_{F t s}$ and $f_{F t u}$ for FRC. These parameters are associated with specific CMODs of a standardized beam. However, the MC2010 lacks specific indications to calculate these parameters in case smaller non-standard specimens are used. The main issue lies in which CMOD should be considered when 

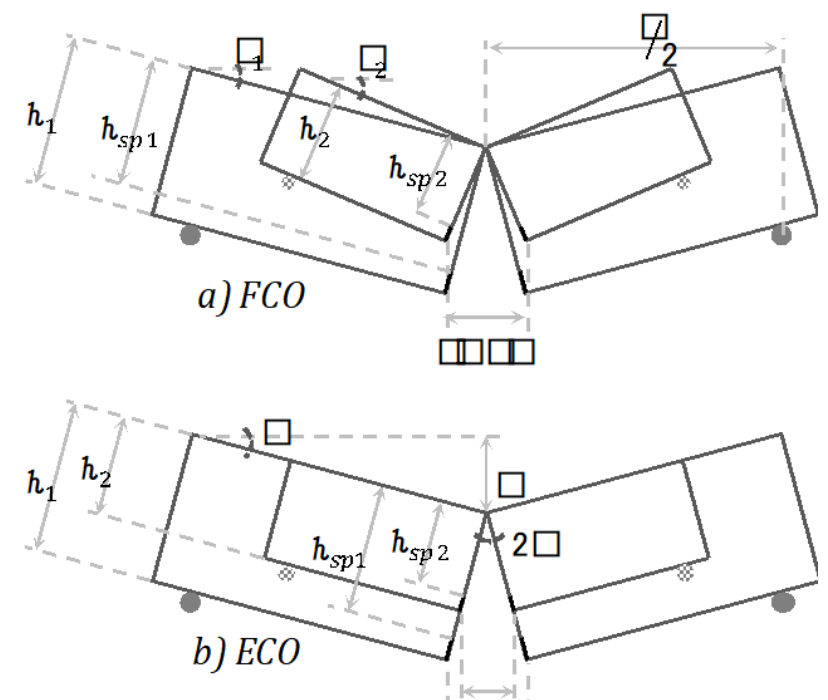
and assumes the use of the same crack opening for any specimen size, thus requiring smaller samples to achieve a greater rotation $\left(\theta_{2}\right)$ than larger samples $\left(\theta_{1}\right)$. The second approach, shown in Fig. 2b and named Equivalent Crack Opening (ECO), is based on the use of crack openings proportional to the beam depth. In such case, the equivalent CMOD of any specimen may be obtained through a relationship between rotation, crack opening and sample depth [19].

\section{$\mathrm{DI}_{2}$}

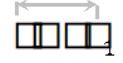

Figure 2. Failure mechanisms of the three-point bending test: a) FCO and b) ECO. 
120 According to the notation indicated in Fig. 2a, which considers $w=C M O D$ and $l_{c s}=$

$121 h_{s p}$, the relation between the strains of different sized specimens in FCO approach can

122 be deduced. Given that crack openings of both beams present the same absolute value,

123 the CMOD of a smaller sample is proportionally wider than the CMOD of a larger

124 sample, thus leading small specimens to present greater strains (Eq. 4).

$$
\begin{aligned}
& \varepsilon_{1}=\frac{C M O D}{h_{s p 1}} ; \varepsilon_{2}=\frac{C M O D}{h_{s p 2}} \\
& \varepsilon_{1} h_{s p 1}=\varepsilon_{2} h_{s p 2} \\
& h_{s p 1}>h_{s p 2} \\
& \varepsilon_{1}<\varepsilon_{2}
\end{aligned}
$$

125 ECO approach assumes a constant rotation $(\theta)$ for any specimen size, thus leading to 126 smaller CMODs and deflections $(\delta)$ in samples of smaller dimensions. This approach 127 results in CMODs that are proportional to the depth of the specimen, leading to identical 128 strains for the different sized beams (Eq. 8). The residual strengths $f_{R 1}$ and $f_{R 3}$ in specimens with non-standard dimensions calculated through ECO are, hence, those associated with sized-equivalent crack openings.

$$
\varepsilon_{1}=\frac{C M O D_{1}}{h_{s p 1}} ; \varepsilon_{2}=\frac{C M O D_{2}}{h_{s p 2}}
$$




$$
\begin{aligned}
& \theta=\frac{C M O D_{1}}{2 h_{s p 1}}=\frac{C M O D_{2}}{2 h_{s p 2}} \\
& \varepsilon_{1}=2 \theta ; \varepsilon_{2}=2 \theta \\
& \varepsilon_{1}=\varepsilon_{2}
\end{aligned}
$$

131 Given that the crack opening is assumed to remain constant for different specimen

132 dimensions with FCO, $\varepsilon_{S L S}$ and $\varepsilon_{U L S}$ decrease while the sample size increases.

133 Conversely, according to ECO, $\varepsilon_{S L S}$ and $\varepsilon_{U L S}$ present identical values for different

134 specimen dimensions due to the use of proportional crack widths and $h_{s p}$. As a result of

135 the proportionality between the crack opening and $h_{s p}$, crack openings calculated

136 through ECO increase linearly with the specimen dimension. These variations of strain

137 in FCO and crack opening in ECO are shown in Fig. 3.
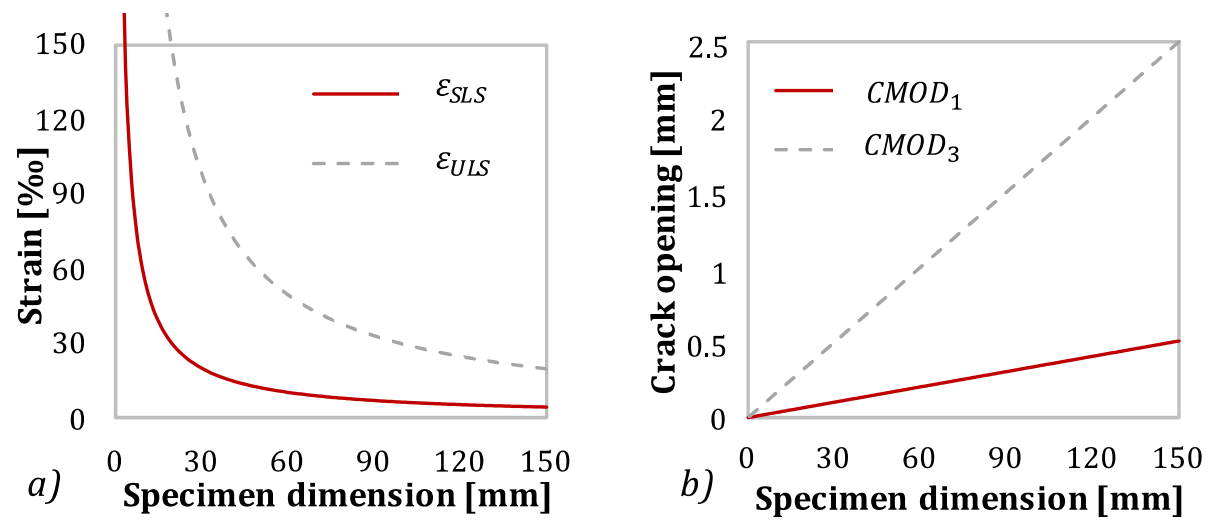

Figure 3. a) Strain according to FCO and b) crack opening with ECO. 


\subsection{Analytical procedure}

142 A back-calculation based on an analysis of evolutionary sections (AES) [20,21] with a multi-layer approach was used to obtain analytically the flexural behaviour of FRC.

144 Given its simplicity and accuracy, similar methods have also been used by several researchers [22-27]. To conduct the AES, several assumptions were adopted:

146 (i) Sections remain plane after loading or imposed strains (hypothesis of Navier$147 \quad$ Bernoulli).

148 (ii) Strain compatibility: perfect bond between concrete and fibres is assumed.

149 (iii) Shear distortion and stresses are negligible and were not considered (hypothesis of $150 \quad$ Euler-Bernoulli).

151 (iv) Internal forces are applied on the symmetrical axis of the section.

152 The material properties in compression and tension are defined through the constitutive

153 law of the MC2010. In the analysis, the cross-section is discretised along its height into 154 layers, and it is assumed that tensile stresses are located at the bottom whereas compression stresses are placed at the top part of the section. The bottom layer of the section is taken as reference for the analysis, where a tensile strain $\varepsilon_{b o t}$ is assumed for

157 the initial stage. Subsequently, a compressive strain at the top $\left(\varepsilon_{t o p}\right)$ is assumed so the curvature $\chi$ and the strain at any layer may be calculated through Eq. 9 according to the combination of Navier-Bernouilli hypothesis with the strain compatibility assumption. 
160 A schematic representation of the discretization and the linear strain distribution is 161 represented in Fig. 4.

$$
\chi=\frac{\varepsilon_{t o p}-\varepsilon_{b o t}}{h}=\frac{\varepsilon_{t o p}-\varepsilon(z)}{Z}
$$

162
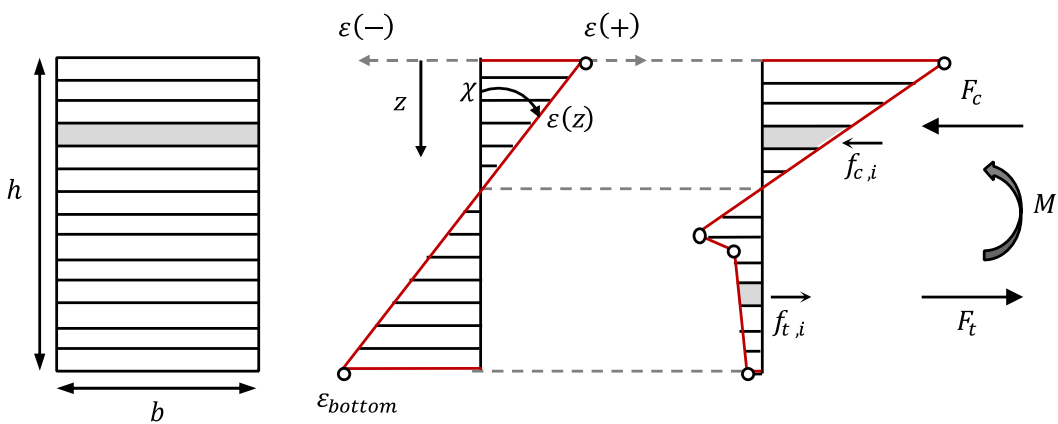

Figure 4. Schematic discretisation of the cross-section and the distributions of strains and stresses.

165 The equilibrium condition between the internal and the external forces is satisfied by imposing Eqs. 10 and 11. For this, the predefined constitutive stress-strain law is used

167 to calculate the stresses out of each strain from the linear distribution. The forces at each

168 layer are calculated through the stresses and are assumed to be applied at the mid-

169 thickness of its corresponding layer.

$$
\begin{aligned}
& N=\int_{A_{c}} f_{c, i} d A_{c, i}+\int_{A_{c}} f_{t, i} d A_{c, i} \\
& M=\int_{A_{c}} z f_{c, i} d A_{c, i}+\int_{A_{c}} z f_{t, i} d A_{c, i}
\end{aligned}
$$


170 If the equilibrium condition is not verified, a new $\varepsilon_{\text {top }}$ is assumed and iterated until the 171 equilibrium is satisfied. At this stage, the internal flexural moment at the section may be 172 calculated. Additionally, the crack opening can be obtained through the strain at the 173 bottom layer and the characteristic length $\left(w=\varepsilon \cdot l_{c s}\right)$.

174 The steps for computing are shown in the flowchart of Fig. 5, using a similar procedure 175 to the one described in previous studies $[25,28]$. The method begins assuming an initial 176 strain at the bottom fibre and calculates the strains at the cross-section by an iterative 177 process checking whether the equilibrium conditions are satisfied. When a result is 178 achieved, the strain at the bottom increases and the iterative process starts over. 


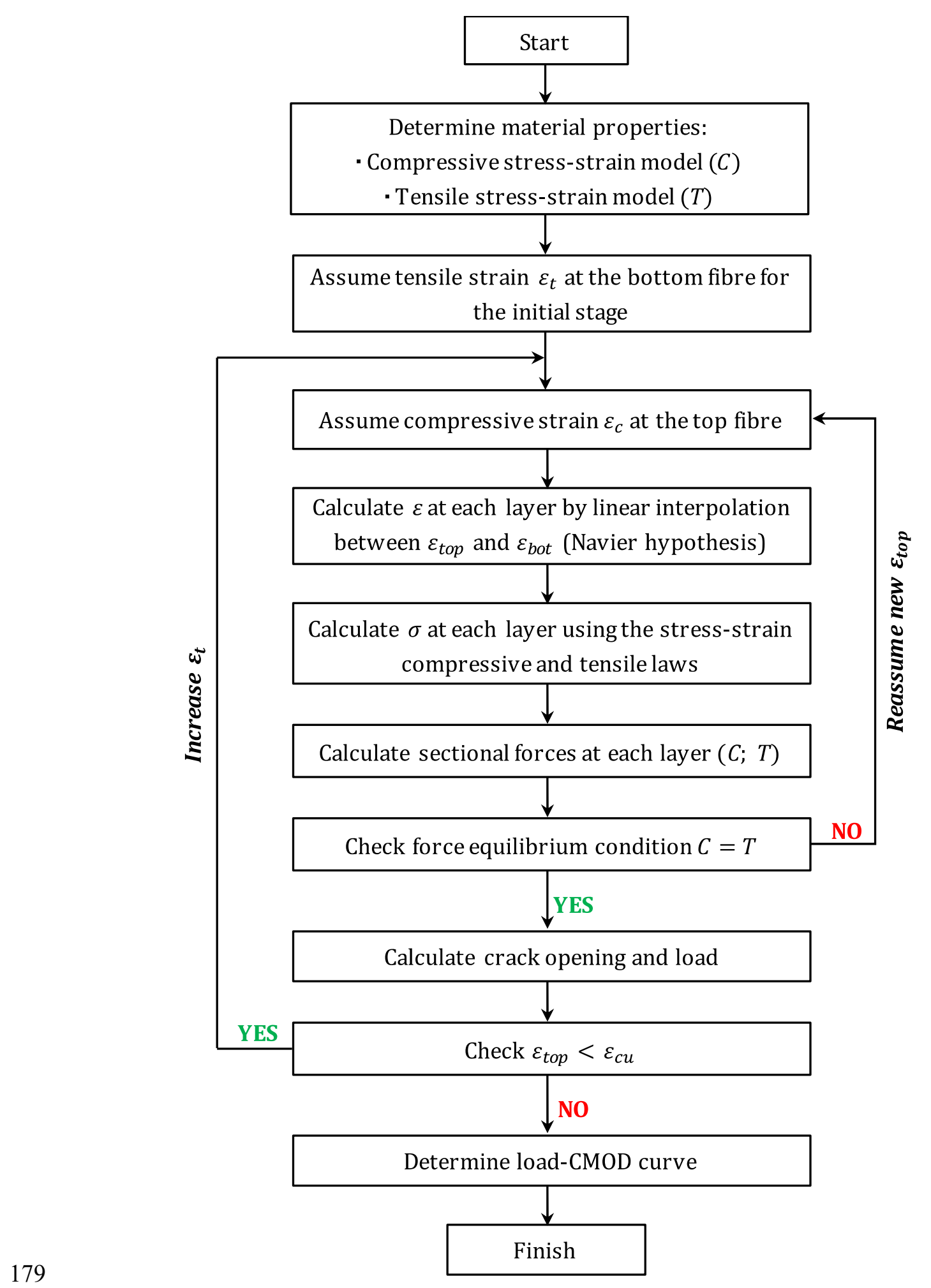

180 Figure 5. Flow chart of the analytical cross-sectional model. 


\section{EXPERIMENTAL PROGRAM}

\subsection{Materials and concrete mixes}

183 One plain concrete mix (M0) and four high-performance fibre reinforced concrete

184 mixes with contents of 90 and $190 \mathrm{~kg} / \mathrm{m}^{3}$ of steel straight microfibres $(l=13 \mathrm{~mm}$,

$185 \phi=0.20 \mathrm{~mm}$ and $f_{y u}=2750 \mathrm{MPa}$ ) were produced (Table 1). As in other studies [29],

186 the content of fibres was increased by replacing an equivalent volume of silica sand to

187 keep constant the content of cement.

188 Nanosilica was introduced in all mixes as a highly reactive pozzolanic material in a

189 content of $5 \%$ over the cement weight (o.c.w.) to enhance the strength. Based on the

190 results of previous research [30], powders with high specific surface increase the water

191 demand to maintain workability, which has a direct influence on the content of water

192 and superplasticizer. Accordingly, mixes M0, M90A and M190A have a lower amount

193 of water than mixes M90B and M190B, which was compensated with a greater content

194 of superplasticizer.

195 Table 1. Concrete mixes $\left[\mathrm{kg} / \mathrm{m}^{3}\right]$.

\begin{tabular}{|c|c|c|c|c|c|}
\hline Materials & Mo & M90A & M190A & M90B & M190B \\
\hline CEM I 52.5R & 800 & 800 & 800 & 800 & 800 \\
\hline Silica sand $3-4 \mathrm{~mm}$ & 1161 & 1131 & 1098 & 1129 & 1098 \\
\hline Filler $\left(\mathrm{CaCO}_{3}\right)$ & 200 & 200 & 200 & 200 & 200 \\
\hline Water & 129 & 129 & 129 & 185 & 185 \\
\hline Nanosilica (o.c.w.) & $5 \%$ & $5 \%$ & $5 \%$ & $5 \%$ & $5 \%$ \\
\hline Superplasticizer (o.c.w.) & $4 \%$ & $4 \%$ & $4 \%$ & $2 \%$ & $2 \%$ \\
\hline Steel fibres & 0 & 90 & 190 & 90 & 190 \\
\hline
\end{tabular}

196 


\subsection{Concrete production and specimens}

198 The concrete was produced using a vertical axis mixer with an automatized system to 199 weight and introduce the dried materials with the specified amount of water. The 200 nanosilica, the superplasticizer and the fibres were introduced to the mix manually 201 through an opening on the mixer. After mixing, the concrete mix was directly poured

202 from the skip to the moulds. A curing layer was sprayed over the free surface of the 203 specimens to prevent the loss of superficial water and a consequent early shrinkage.

204 For each concrete mix, 3 cubic specimens of $150 \times 150 \mathrm{~mm}, 6$ specimens of $100 \times 100 \mathrm{~mm}, 9$ cubic specimens of $40 \times 40 \mathrm{~mm}$ and 3 cylindrical $\phi 150 \times 300 \mathrm{~mm}$ samples were produced. Moreover, 3 prismatic samples with dimensions of $150 \times 150 \times 600 \mathrm{~mm}, 6$ samples of $100 \times 100 \times 400 \mathrm{~mm}$ and 9 samples of $40 \times 40 \times 160 \mathrm{~mm}$ were cast, thus resulting in a total amount of 90 prismatic beams of three dimensions. The use of microfibres was necessary given that the small specimens limit the size of the fibres. The cubic specimens were used to perform compressive tests according with EN 12390-3 [31], the cylindrical samples to assess the modulus of

212 elasticity following the indications of EN 12390-13 [32] and the prismatic specimens to

213 determine the flexural and residual strength through the three-point bending test based on the standard EN 14651 [15].

The dimensions of the specimens for the three-point bending test, as specified in EN 14651, are prisms of $150 \times 150 \times 600 \mathrm{~mm}$. To conduct the tests with smaller specimens

$217100 \times 100 \times 400$ and $40 \times 40 \times 160 \mathrm{~mm}$, the notch depth and the span length were adjusted 218 according to the dimensions of these samples. Following previous research [33-35], the 

depth-span and depth-notch ratios of the $150 \times 150 \times 600 \mathrm{~mm}$ beams were kept constant

220 to maintain the proportions between the dimensions of the beams. Table 2 shows the

221 effective depth $\left(h_{s p}\right)$ and the span of the three different prisms sizes. Bending tests of 222 all samples, regardless of their dimension, were performed by CMOD control at a speed 223 of $0.05 \mathrm{~mm} / \mathrm{min}$ up to a CMOD of $1.0 \mathrm{~mm}$. Test rate was subsequently increased to 0.2 $224 \mathrm{~mm} / \mathrm{min}$ until a CMOD of $4.0 \mathrm{~mm}$, which was considered the end of the test.

Table 2. Characteristic dimensions of the specimens for the three-point bending test.

\begin{tabular}{|c|c|c|}
\hline Specimen dimension [mm] & Effective depth $h_{s p}[\mathrm{~mm}]$ & Span [mm] \\
\hline $150 \times 150 \times 600$ & 125.0 & 500 \\
\hline $100 \times 100 \times 400$ & 83.3 & 333 \\
\hline $40 \times 40 \times 160$ & 33.3 & 133 \\
\hline
\end{tabular}

\section{ANALYSIS OF RESULTS}

\subsection{Compressive strength and modulus of elasticity}

229 The average results of the compressive strength for three different sized cubic

230 specimens and the results of the modulus of elasticity performed on standard cylindrical 231 samples are detailed in Table 3.

232 Table 3. Results of compressive strength and modulus of elasticity.

\begin{tabular}{lllllllll}
\hline \multirow{3}{*}{ Mix } & \multicolumn{4}{l}{ Compressive strength [MPa] } & \multicolumn{4}{c}{ Modulus of elasticity [MPa] } \\
\cline { 2 - 9 } & $\mathbf{1 5 0 x 1 5 0} \mathbf{~ m m}$ & $\mathbf{1 0 0 x 1 0 0} \mathbf{~ m m}$ & $\mathbf{4 0 x 4 0} \mathbf{~ m m}$ & \multicolumn{1}{c}{$\mathbf{1 5 0 x 3 0 0} \mathbf{~ m m}$} \\
\cline { 2 - 9 } & Average & $\mathbf{C V}$ & Average & $\mathbf{C V}$ & Average & $\mathbf{C V}$ & Average & CV \\
\hline M0 & 111.2 & $1.8 \%$ & 96.9 & $2.0 \%$ & 97.4 & $7.2 \%$ & 36429 & $0.5 \%$ \\
M90A & 115.9 & $0.7 \%$ & 109.5 & $2.9 \%$ & 126.8 & $8.4 \%$ & 36337 & $0.5 \%$ \\
M190A & 117.2 & $0.5 \%$ & 115.0 & $3.4 \%$ & 133.6 & $6.4 \%$ & 37674 & $0.5 \%$ \\
M90B & 108.8 & $2.4 \%$ & 102.1 & $1.6 \%$ & 122.8 & $7.9 \%$ & 32807 & $0.3 \%$ \\
M190B & 100.3 & $6.8 \%$ & 103.3 & $1.9 \%$ & 124.9 & $6.4 \%$ & 34095 & $9.3 \%$ \\
\hline
\end{tabular}


234 A comparison between FRC mixes with different water-cement ratios $(w / c)$ reveals an 235 expected reduction of the compressive strength for higher $w / c$ ratios. This effect may 236 also be appreciated in the modulus of elasticity, with lower values for higher $w / c$ ratios.

237 The higher content of water in the mix with greater $w / c$ ratios is the main responsible 238 of inducing a higher porosity in the concrete matrix and, therefore, reducing both the 239 compressive strength and the modulus of elasticity.

240 In line with the results reported in other studies [36-38] the addition of fibres slightly 241 increased the compressive strength except in mixes M90B and M190B, which presented 242 a reduction of the compressive strength from 108.8 to $100.3 \mathrm{MPa}$. For the case of mix 243 M190B, the scatter of the compressive strength of 150x150 mm cubic specimens and 244 the modulus of elasticity increased with respect to the rest of the mixes. These results might be attributed to early setting initiation while casting due to the large amount of specimens and the long time required for casting. Notice, however, how the

247 compressive strength and the scatter of cubic specimens $100 \times 100 \mathrm{~mm}$ and $40 \times 40 \mathrm{~mm}$

248 follow the line of the results of the rest of the mixes. Consequently, the generalised 249 increase of strength may be attributed to a certain confinement effect of the microfibers, 250 inhibiting and delaying microcracking propagation produced by compression stresses 251 when above $0.4 f_{c m}$.

\section{$252 \quad 4.2 \quad$ Flexural strength}

253 The average flexural strengths of the three-point bending tests conducted on $254150 \times 150 \times 600 \mathrm{~mm}, 100 \times 100 \times 400 \mathrm{~mm}$ and $40 \times 40 \times 160 \mathrm{~mm}$ specimens are shown in 255 Table 4 . The values show the strengths at the limit of proportionality $\left(f_{L O P}\right)$ and at 
256 CMODs of $0.5,1.5,2.5$ and $3.5 \mathrm{~mm}\left(f_{R 1}, f_{R 2}, f_{R 3}\right.$ and $\left.f_{R 4}\right)$. These results were

257 calculated as described in the standard EN 14651.

258 Table 4. Average flexural strengths of M90A, M190A, M90B and M190B in specimens 259 of $150 \times 150 \times 600 \mathrm{~mm}, 100 \times 100 \times 400 \mathrm{~mm}$ and $40 \times 40 \times 160 \mathrm{~mm}$.

\begin{tabular}{|c|c|c|c|c|c|c|c|c|c|c|c|}
\hline \multirow{3}{*}{ Mix } & \multirow{3}{*}{$\begin{array}{l}\text { Size } \\
{[\mathrm{mm}]}\end{array}$} & \multicolumn{10}{|c|}{ Flexural strength } \\
\hline & & $f_{L O P}$ & $\mathrm{CV}$ & $f_{R 1}$ & $\mathrm{CV}$ & $f_{R 2}$ & $\mathrm{CV}$ & $f_{R 3}$ & $\mathrm{CV}$ & $f_{R 4}$ & $\mathrm{CV}$ \\
\hline & & [MPa] & {$[\%]$} & [MPa] & {$[\%]$} & [MPa] & [\%] & [MPa] & [\%] & [MPa] & [\%] \\
\hline \multirow{3}{*}{ M90A } & 40 & 10.38 & 4.4 & 16.00 & 5.7 & 14.09 & 6.2 & 11.92 & 7.6 & 10.00 & 8.7 \\
\hline & 100 & 9.08 & 8.4 & 13.98 & 2.1 & 13.97 & 2.1 & 12.53 & 3.9 & 10.89 & 4.7 \\
\hline & 150 & 8.02 & 6.5 & 14.58 & 5.8 & 14.63 & 4.0 & 13.03 & 3.8 & 11.18 & 3.7 \\
\hline \multirow{3}{*}{ M190A } & 40 & 9.80 & 15.6 & 21.17 & 21.7 & 17.46 & 22.8 & 13.44 & 20.7 & 10.61 & 19.1 \\
\hline & 100 & 8.83 & 4.2 & 23.01 & 8.9 & 21.85 & 10.7 & 18.00 & 13.8 & 14.18 & 14.4 \\
\hline & 150 & 9.54 & 6.8 & 17.83 & 7.6 & 16.96 & 2.7 & 14.73 & 4.6 & 11.99 & 4.3 \\
\hline \multirow{3}{*}{ M90B } & 40 & 8.67 & 10.9 & 14.54 & 9.7 & 12.71 & 10.2 & 10.31 & 13.1 & 8.30 & 16.7 \\
\hline & 100 & 8.61 & 3.8 & 13.72 & 12.9 & 13.07 & 11.7 & 11.54 & 11.4 & 9.80 & 12.3 \\
\hline & 150 & 7.86 & 2.3 & 12.06 & 6.9 & 11.99 & 4.0 & 10.36 & 3.9 & 8.69 & 3.6 \\
\hline \multirow{3}{*}{ M190B } & 40 & 8.06 & 7.3 & 23.78 & 14.9 & 20.17 & 19.2 & 15.91 & 23.3 & 12.64 & 23.7 \\
\hline & 100 & 10.09 & 3.4 & 19.07 & 10.4 & 17.32 & 13.2 & 13.88 & 15.2 & 10.77 & 15.7 \\
\hline & 150 & 8.16 & - & 16.35 & - & 15.75 & - & 13.00 & - & 10.37 & - \\
\hline
\end{tabular}


261 Increasing the content of fibres from 90 to $190 \mathrm{~kg} / \mathrm{m}^{3}$ enhanced $f_{L O P}$ especially from 262 mix M90A to M190A, with M190A presenting a $f_{L O P}$ approximately $15 \%$ higher than 263 M90A. These results are similar to those reported in previous studies using microfibres 264 [39]. In line with the results of other researchers [40], a comparison of $f_{L O P}$ of mixes 265 M90B and M190B presents a variation of only 3.8\% given that $f_{L O P}$ is mainly 266 influenced by the properties of the matrix and the $w / c$ ratio $[41,42]$.

267 The post-cracking results exhibited expected trends according to the content of fibres 268 and the $w / c$ ratios. In both groups of mixes (A and B), the increasing amount of fibres 269 entailed greater residual stresses while the reduction of the $w / c$ ratio led to greater 270 bending stresses. Notice also that the scatter of the residual strengths is considerably 271 low in comparison with the results of other studies $[42,43]$. This is mainly attributed to 272 the higher fibre density in the cracked surface $[36,44]$ which provides a higher 273 homogeneity to flexural stresses.

274 The average flexural strength is expressed in terms of stress-CMOD in Fig. 6. The 275 results are shown for the four mixes analysed and the three dimensions of specimens tested. Results are shown to crack openings up to $4 \mathrm{~mm}$, revealing the performance differences exhibited by the dimension of the specimen tested. 

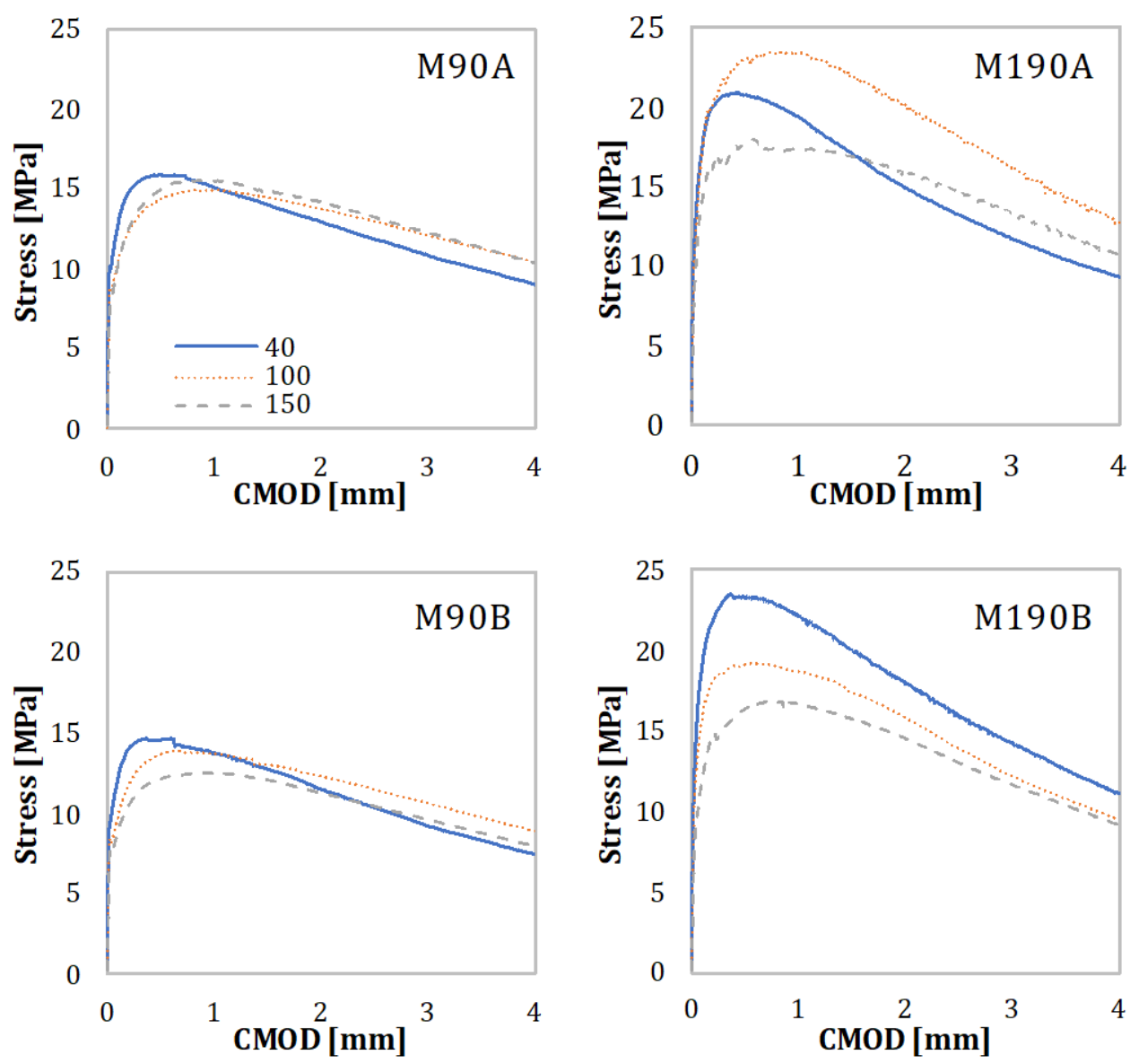

Figure 6. Average flexural strength in terms of stress-CMOD.

280 All mixes exhibit a hardening behaviour after cracking up to the maximum residual

281 strength and a clear influence of the specimen size on the performance. As shown by

282 other authors [45], the strength generally decreased as the specimen size increased. In

283 mixes M90A and M90B, with a lower content of fibres, although there are performance

284 differences among the different specimen dimensions, such differences are not as

285 noticeable as in mixes M190A and M190B. These results indicate, therefore, the clear

286 influence of the fibres on concrete performance, which can be mainly attributed to a

287 preferential orientation and distribution towards the crack surface perpendicular

288 direction in small specimens. 
The observations in M190A differ with the findings of previous studies $[4,46]$ with similar contents and types of fibres. Nonetheless, M190A was produced with a

291 considerably low $w / c$ ratio and a high content of fibres $\left(0.16\right.$ and $190 \mathrm{~kg} / \mathrm{m}^{3}$,

292 respectively) in comparison to the aforementioned studies. The combination of these

293 two variables results in a lower flowability of concrete [47], which directly affects the

294 orientation of the fibres in the element and the flexural strength [48].

295

296

297

298

299

300

301

302

303

304

305

The average $f_{L O P}$ and the average maximum strength of the four mixes are shown in Fig. 7 represented according to the specimen size. The general trend indicates a reduction of both strengths while increasing the dimension of the specimen.
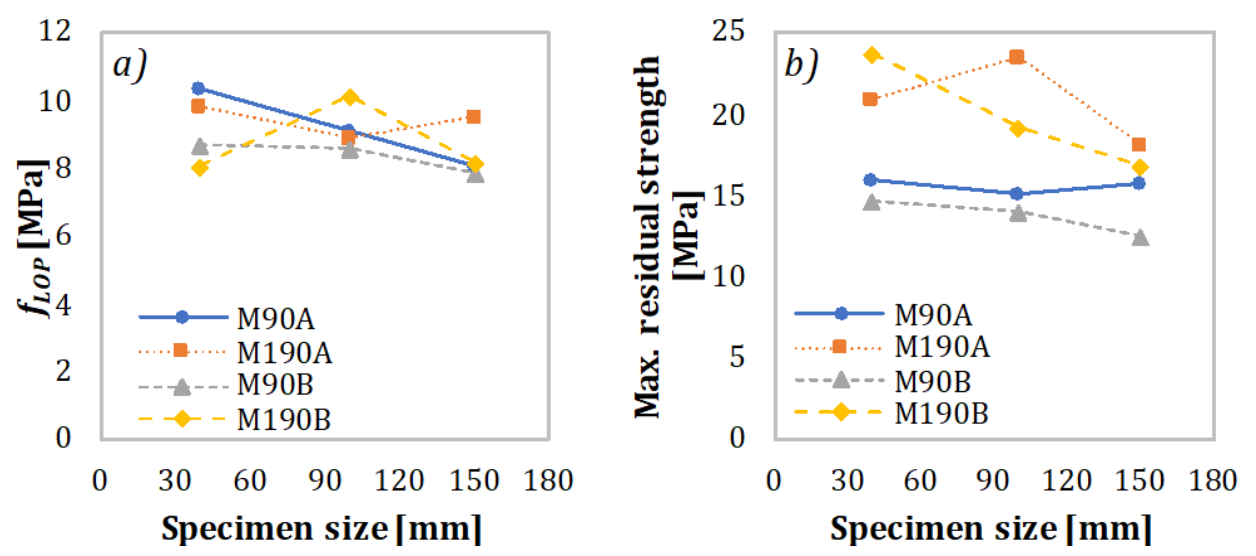

Figure 7. Size effect on a) $f_{\text {LOP }}$ and b) maximum strength.

The results of the 40x40x160 mm specimens in Fig. 7a confirms the minor influence of the content of fibres on $f_{L O P}$, showing that the $w / c$ ratio is the main responsible of the differences in the cracking strength. The lower strength of mixes with $190 \mathrm{~kg} / \mathrm{m}^{3}$ with regard to their counterpart with $90 \mathrm{~kg} / \mathrm{m}^{3}$ confirms that increasing the content of fibres does not necessarily lead to a greater cracking strength. Indeed, the lower results of mixes M190A and M190B with regard to M90A and M90B, respectively, may be a 
consequence of a higher induced porosity in the matrix as a result of the higher content

307 of fibres $[49,50]$. Increasing the content of fibres enhanced the maximum residual

308 strength (Fig. 7b), which is a direct effect of the greater number of fibres in the cracked

309 section $[48,51]$. These results also indicate that a lower $w / c$ ratio improved the bond

310 strength at the fibre-matrix interface [52].

\subsection{Constitutive models}

312 The constitutive model for FRC was calculated for each mix and specimen dimension to

313 conduct the analytical calculations, obtaining both $\varepsilon_{S L S}$ and $\varepsilon_{U L S}$ following the relation

314 between crack opening and strain of the MC2010. Considering the characteristic length

$315 l_{c s}$ of each specimen as the effective depth $h_{s p}$, CMODs and strains at SLS and ULS for

316 each approach analysed (FCO and ECO) take the values shown in Table 5.

317 Table 5. Crack openings and strains, according to FCO and ECO.

\begin{tabular}{|c|c|c|c|c|c|c|c|c|c|}
\hline \multirow[b]{2}{*}{$\begin{array}{l}\text { Characteristic } \\
\text { length }\end{array}$} & \multirow[b]{2}{*}{$\begin{array}{l}\text { Specimen } \\
\text { dimension }\end{array}$} & \multicolumn{4}{|c|}{ Full crack opening (FCO) } & \multicolumn{4}{|c|}{ Equivalent crack opening (ECO) } \\
\hline & & $\begin{array}{l}C M O D_{1} \\
{[\mathrm{~mm}]}\end{array}$ & $\begin{array}{l}\mathrm{CMOD}_{3} \\
{[\mathrm{~mm}]}\end{array}$ & $\begin{array}{l}\varepsilon_{S L S} \\
(\% 0)\end{array}$ & $\begin{array}{l}\varepsilon_{U L S} \\
(\% 0)\end{array}$ & $\begin{array}{l}C M O D_{1} \\
{[\mathrm{~mm}]}\end{array}$ & $\begin{array}{l}\mathrm{CMOD}_{3} \\
{[\mathrm{~mm}]}\end{array}$ & $\begin{array}{l}\varepsilon_{S L S} \\
(\% 0)\end{array}$ & $\begin{array}{l}\varepsilon_{U L S} \\
(\% 0)\end{array}$ \\
\hline \multirow{3}{*}{$l_{c s}=h_{s p}$} & $40 \mathrm{~mm}$ & 0.50 & 2.50 & 15.00 & 75.00 & 0.13 & 0.67 & 4.00 & 20.00 \\
\hline & $100 \mathrm{~mm}$ & 0.50 & 2.50 & 6.00 & 30.00 & 0.33 & 1.67 & 4.00 & 20.00 \\
\hline & $150 \mathrm{~mm}$ & 0.50 & 2.50 & 4.00 & 20.00 & 0.50 & 2.50 & 4.00 & 20.00 \\
\hline \multirow{3}{*}{$l_{c s}=125$} & $40 \mathrm{~mm}$ & 0.50 & 2.50 & 4.00 & 20.00 & 0.13 & 0.67 & 1.04 & 5.36 \\
\hline & $100 \mathrm{~mm}$ & 0.50 & 2.50 & 4.00 & 20.00 & 0.33 & 1.67 & 2.64 & 13.36 \\
\hline & $150 \mathrm{~mm}$ & 0.50 & 2.50 & 4.00 & 20.00 & 0.50 & 2.50 & 4.00 & 20.00 \\
\hline
\end{tabular}

319 Both strengths $f_{\text {Fts }}$ and $f_{\text {Ftu }}$ of the constitutive law are calculated for each geometry at

$320 \mathrm{CMOD}_{1}$ and $\mathrm{CMOD}_{3}$, respectively. Given that the crack openings for both approaches

321 are different, $f_{F t s}$ and $f_{F t u}$ result in different values if calculated for FCO or ECO. A 
322 comparison between the constitutive laws for the three specimen dimensions according

323 to FCO and ECO and the experimental results expressed in terms of stress-rotation are

324 shown in Fig. 8.

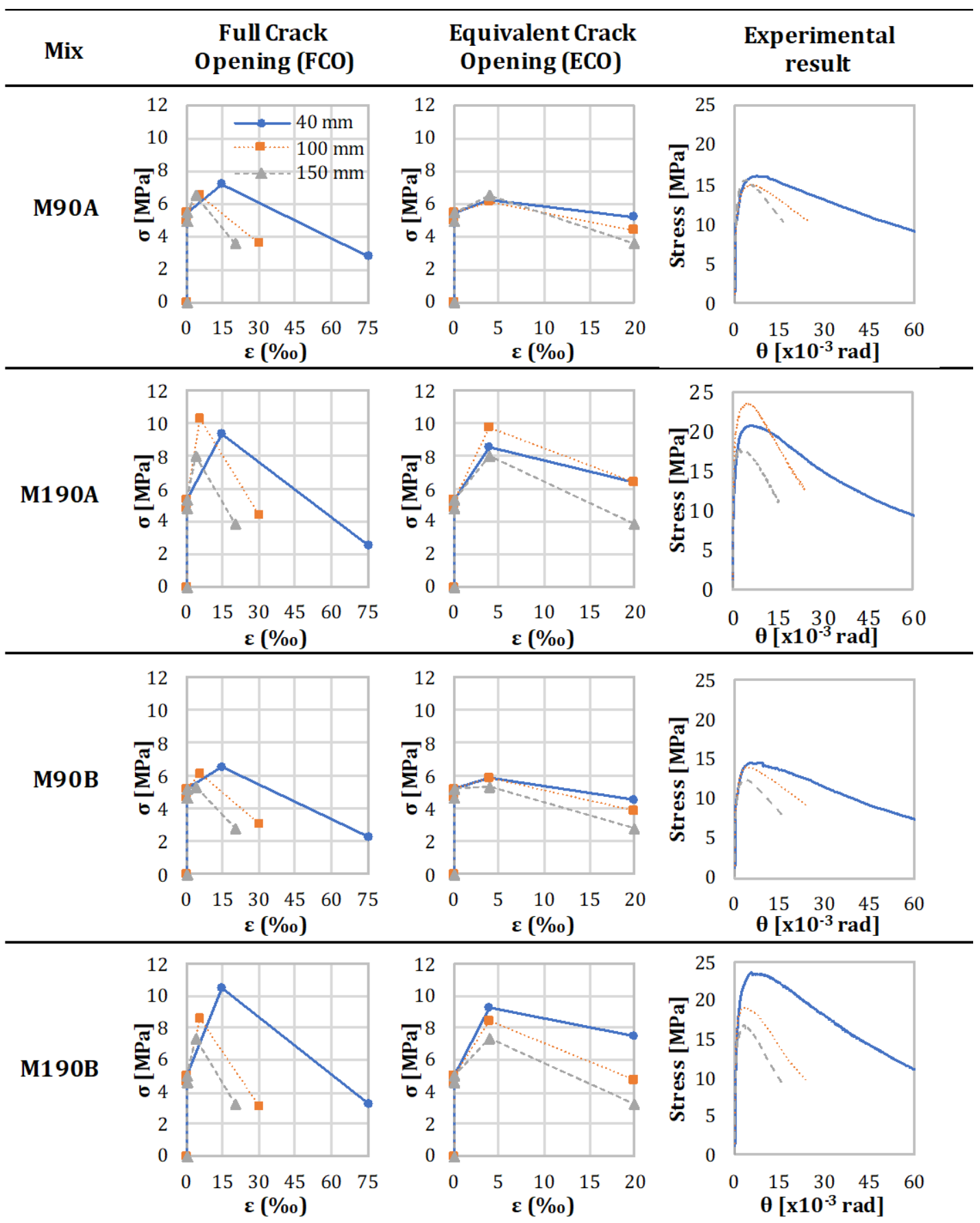

326 Figure 8. Constitutive laws, according to FCO and ECO and experimental results. 
The main difference between both approaches lies in the strains at SLS and ULS. The greater strains in smaller specimens due to the proportionally higher crack opening are evidenced in the shape of the constitutive model calculated through FCO, this presenting lower strains at both SLS and ULS while increasing the specimen dimension. This result contrasts with the results of the constitutive model determined with ECO since the crack openings for each specimen dimension are proportional to the specimen size, and the strains remain constant regardless of the dimension of the element.

The constitutive model curves calculated with both approaches follow similar trends with smaller specimens showing greater strengths. A comparison of the experimental stress-rotation results with the constitutive laws indicates a greater resemblance of the experimental stress-rotation to the constitutive model calculated through FCO given the greater rotations achieved by small elements. This is mainly caused by the two defining parameters: the strains and the stresses of the constitutive model, since the assumptions of ECO entail that the rotation $\theta$ and the strain $\varepsilon$ are directly proportional.

341 The strength parameters $f_{F t s}$ and $f_{F t u}$ of the 4 mixes calculated according to both FCO and ECO for the three specimen sizes are shown in Fig. 9. The results reveal that the influence of the fibre content is more evident in $f_{F t s}$ than in $f_{F t u}$, this suggesting that the reinforcing effect of the micro-steel fibres under analysis is greater at reduced strains and crack openings and even greater in smaller specimens than in large samples. According to FCO approach in specimens of $40 \mathrm{~mm}$, M190A and M190B present $f_{\text {Fts }}$

347 values around 30\% and 60\% higher than M90A and M90B, respectively. These results

348 contrast with the counterpart in specimens of $150 \mathrm{~mm}$, whose $f_{F t s}$ variation for FCO changes from $30 \%$ to $22 \%$ and from $60 \%$ to $36 \%$. 

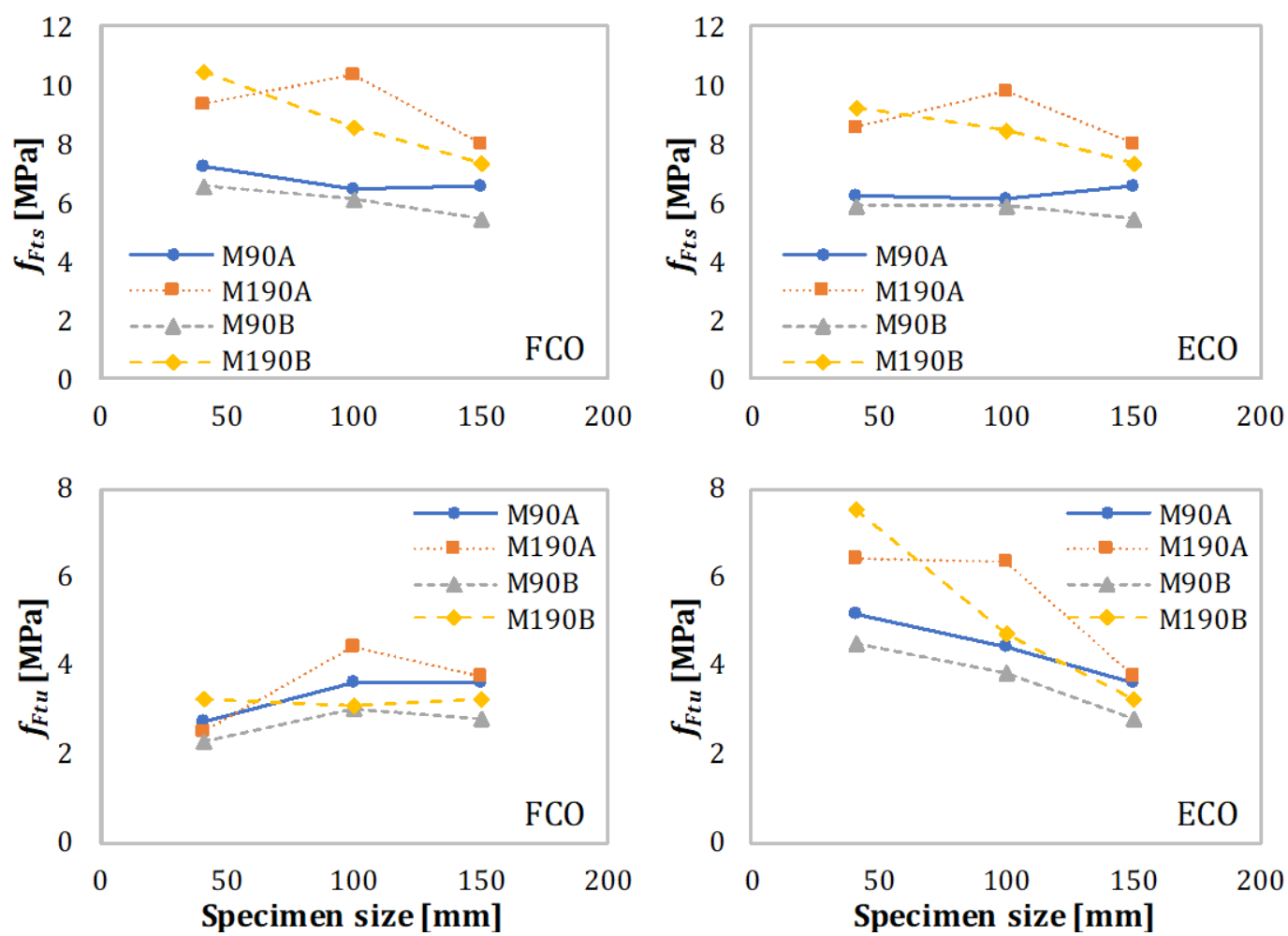

351 Figure 9. Size effect on $f_{F t s}$ and $f_{F t u}$ according to FCO and ECO approaches.

352 A comparison between both approaches shows a strong similarity between FCO and

353 ECO in terms of $f_{F t s}$, although there are relevant differences between approaches in

$354 f_{F t u}$. In the case of FCO, $f_{F t u}$ presents a slightly increasing trend as the dimensions of

355 the samples increase. Conversely, $f_{F t u}$ exhibits a decreasing trend with the specimen

356 size when calculated according to ECO approach given that $f_{F t u}$ is determined for a

357 smaller crack opening in small specimens.

\subsection{FCO approach}

359 Back-analyses were conducted considering the constitutive laws determined through the

360 FCO approach of three different dimensions of the specimens. All the analytical curves

361 were obtained assuming a characteristic length $l_{c s}=125 \mathrm{~mm}$ to predict the behaviour of 
an element with the same dimension regardless of the size of the specimen used to

363 calculate the constitutive law. The analytical results predicting the behaviour of a standard

364 specimen using the constitutive equations determined through samples of 40, 100 and 150

$365 \mathrm{~mm}$ are displayed in Fig. 10, showing a comparison with the experimental results of the

366 150x150x600 mm beams. Such comparison shows up to which extent using the parameters of small specimens influence the analytical prediction of a specific element.
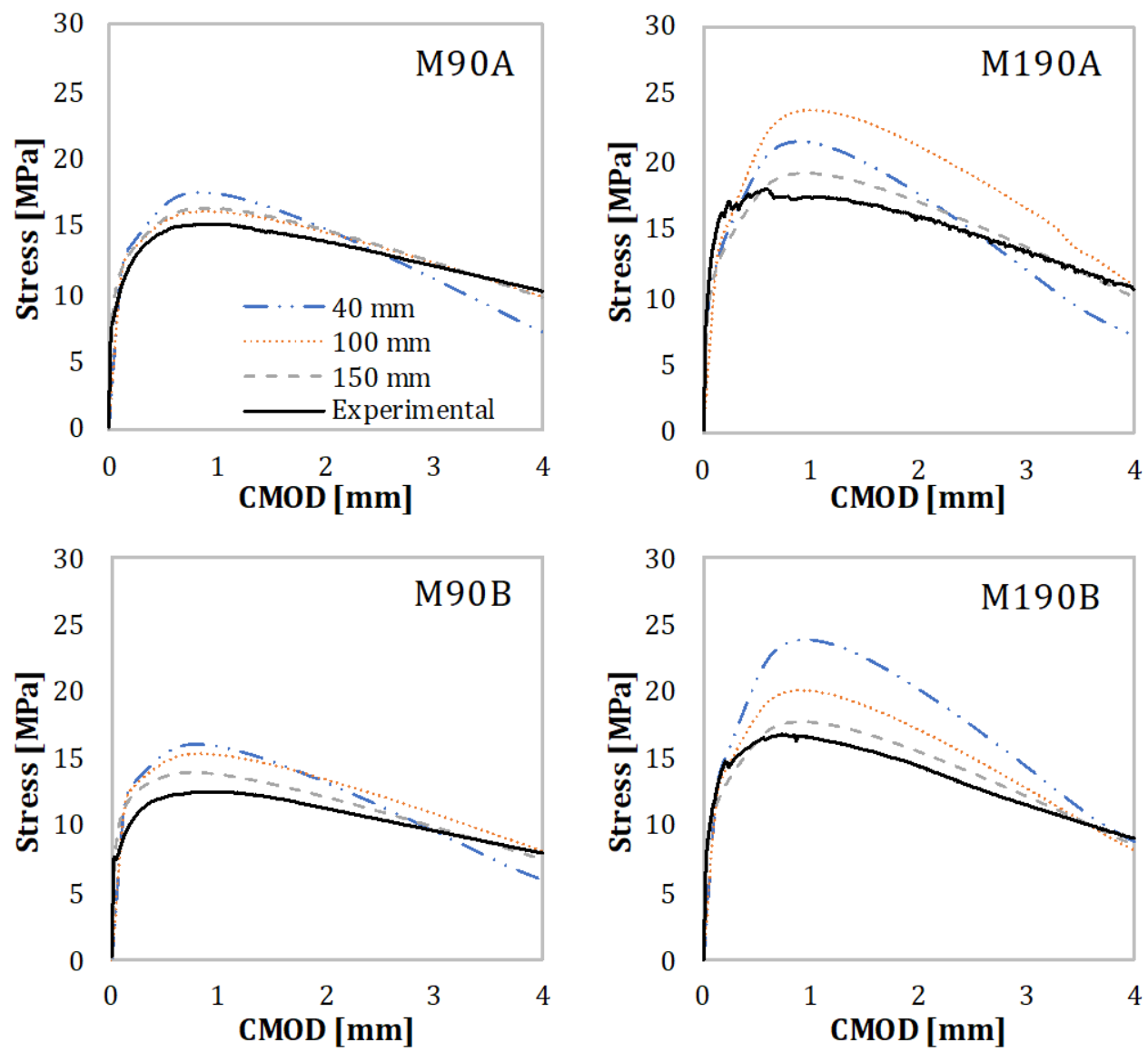

Figure 10. Comparison between analytical results for $150 \mathrm{~mm}$ element through FCO and experimental curves.

371 The results reveal a generalised increasing size effect while considering smaller

372 dimensions of specimens to predict the flexural response of an element of $150 \mathrm{~mm}$. In 
373 this line, the results obtained through specimens of $40 \mathrm{~mm}$ exhibit the greatest differences 374 with respect to the experimental results. This is already reflected in the results of the 375 constitutive laws and the flexural results of smaller specimens, since for given crack 376 openings small samples present greater strengths.

\section{$377 \quad 4.5$ Comparison between FCO and ECO}

378 Based on the constitutive models of Fig. 8, a comparison between the experimental

379 curves of the four mixes and the analytical curves obtained with AES is shown in Fig.

38011 . The results are shown in terms of stress-rotation up to $\theta=0.02 \mathrm{rad}$, which

381 corresponds to a strain at the notch $\varepsilon=40 \%$. Notice that in specimens of $150 \mathrm{~mm}$

382 only one analytical curve is presented since for this dimension both FCO and ECO

383 constitutive curves coincide. These results reveal that the analytical stress-rotation

384 curves present a more accurate fitting when determined according to the ECO approach

385 when analysing small elements. 

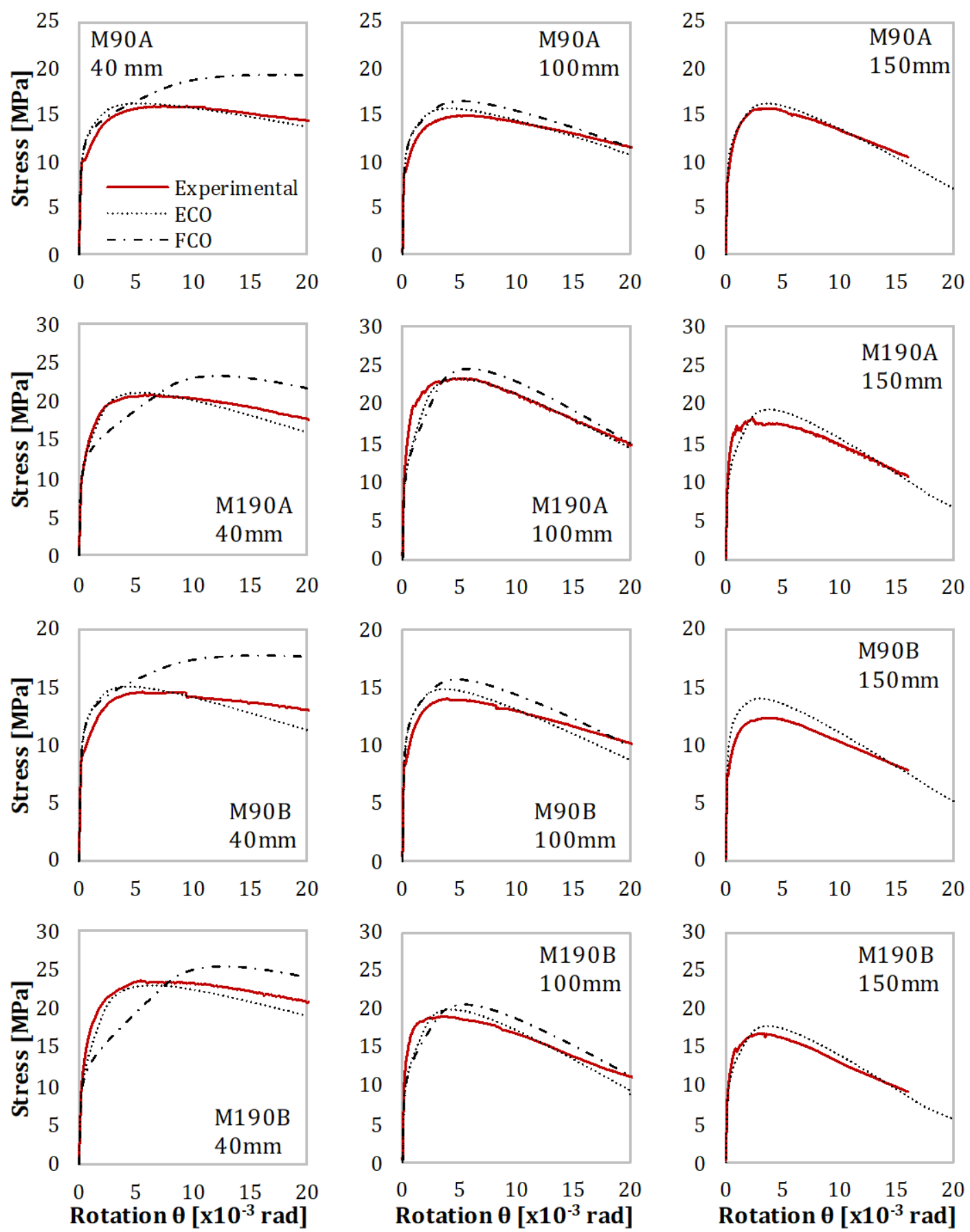

387 Figure 11. Comparison between experimental and MC2010 results.

388 There are no significant differences between approaches and the experimental results up

389 to the cracking point since up to this point the constitutive law is defined according to

390 the tensile strength of plain concrete and both approaches share the same parameters. 
From this point onwards, and at the cracked stage, the differences between the experimental and the analytical results are greater when using the FCO approach. These differences for FCO increase for higher contents of fibres and smaller specimens.

394 The differences between FCO and experimental results at small rotations are bigger for mixes with $190 \mathrm{~kg} / \mathrm{m}^{3}$, if compared with mixes blended with $90 \mathrm{~kg} / \mathrm{m}^{3}$. At $\theta=3.5$. $10^{-3} \mathrm{rad}, \mathrm{FCO}$ yields a $15 \%$ lower strength for M190A than the experimental result, whereas the difference at the same rotation between ECO and the experimental values is only $1.5 \%$. At $\theta=20 \cdot 10^{-3} \mathrm{rad}$, the differences with respect to the experimental results were $21 \%(\mathrm{FCO})$ and $11 \%(\mathrm{ECO})$. As in the case of mixes with $90 \mathrm{~kg} / \mathrm{m}^{3}$, mix M190B presented analogous results to M190A.

For specimens of $40 \mathrm{~mm}$ and mix M90A, FCO and ECO presented a strength compared 402 to the experimental results $2.8 \%$ and $5.2 \%$ higher at $\theta=3.5 \cdot 10^{-3} \mathrm{rad}$, respectively. At $\theta=20 \cdot 10^{-3} \mathrm{rad}$, the strength with FCO approach increased from $2.8 \%$ to $33 \%$, whereas the difference in ECO at this rotation remained 5.6\% below the experimental value. Similar trends and results are obtained with mix M90B. In specimens of $100 \mathrm{~mm}$, the differences between analytical and experimental results shrank. Almost identical results were obtained with FCO and ECO up to a rotation of approximately $\theta=2.5 \cdot 10^{-3} \mathrm{rad}$ in M90A, overestimating the experimental results at this rotation in $8.7 \%$ and $8.5 \%$, respectively. Regardless of the similarities between 410 approaches, at greater rotations FCO provides higher strengths than both ECO and the experimental curve at greater rotations. In mixes M190A and M190B, both FCO and ECO present again similar results although underestimate the experimental value up to a 
rotation that corresponds approximately to the maximum flexural strength. After this,

414 ECO presents more accurate results than FCO, which again slightly overestimates the

415 results of the descending branch of the curve.

416 The analytical curve in specimens $150 \mathrm{~mm}$ represents both FCO and ECO approaches.

417 It shows a reasonable fitting, albeit it overestimates the results if compared to the

418 experimental values. The most accurate fitting occurs for M90A, while the greatest

419 overestimation takes place in M90B.

\subsection{Neutral axis and stress distributions}

421 The results of the AES provide the strains at the bottom and at the top layer of the section to determine the neutral axis depth assuming the hypothesis of NavierBernouilli. The stress distributions and the relative position of the neutral axis to the specimen depth $\left(x_{n} / h\right)$ obtained through the AES for a CMOD of $0.5 \mathrm{~mm}$ and a rotation of $5 \cdot 10^{-3} \mathrm{rad}$ are shown in Fig. 12.

The results reveal the influence of the control parameter (CMOD or rotation) on the relative depth of the neutral axis depth $x_{n} / h$ based on the strains and stresses patterns that satisfy the sectional equilibrium. If the crack opening is set to a certain CMOD regardless of the dimension of the specimen, the neutral axis leads to a lower $x_{n} / h$ while the size of the element decreases given that $\varepsilon_{b o t}$ is greater due to the relation between the crack opening and the effective depth of the specimen $\left(\varepsilon=w / l_{c s}\right)$, thus shifting the neutral axis upwards the cross-section with regard to larger samples (see Fig. 12). Conversely, a constant rotation $\theta$ entails an identical $\varepsilon_{b o t}$ regardless of the dimension of the element given that the strain is determined as a function of the rotation 
$435(\varepsilon=\theta / 2)$. This leads to the same relative position of the neutral axis $x_{n} / h$ when using 436 elements with different effective depths.
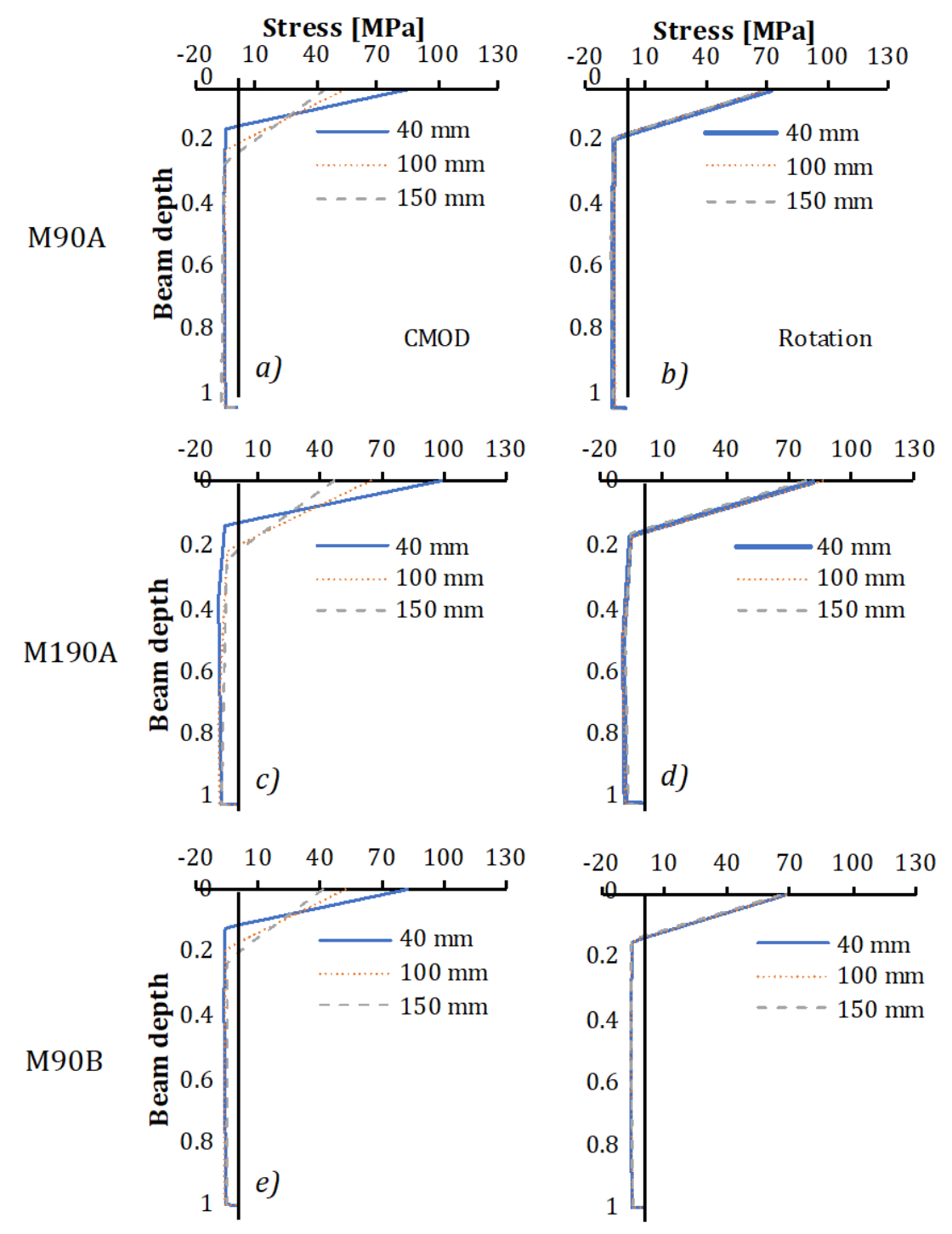

437
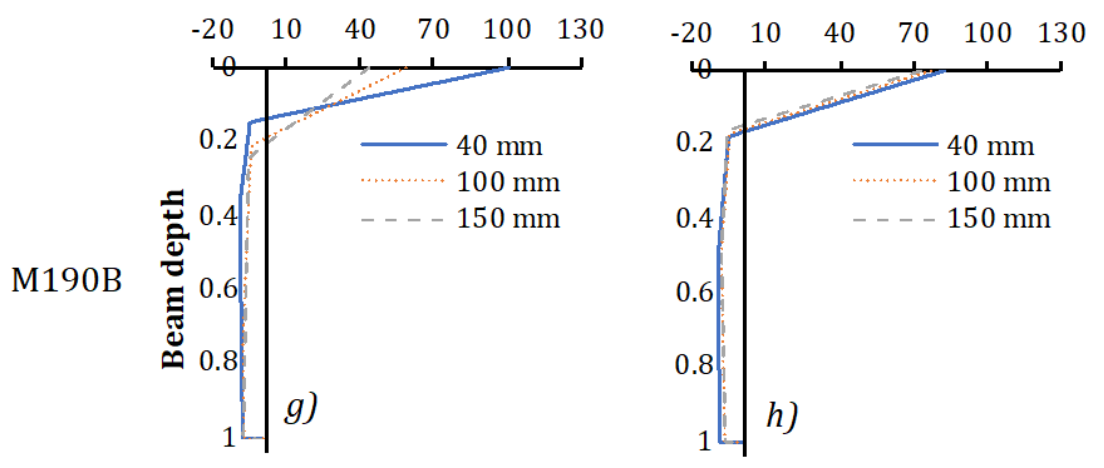

438 Figure 12. Stress distribution at the cross-section and relative neutral axis depth. 
439 The position of the neutral axis $x_{n} / h$ is extended to additional values of CMOD (FCO)

440 and rotation (ECO) for different flexural levels (Fig. 13) for mix M90A. For the rest of

441 the three mixes, similar curves might be obtained given the slight differences in the

442 neutral axis depth results shown in Fig. 12. Three curves - one for each specimen

443 dimension - are obtained for both CMOD and rotation.

444
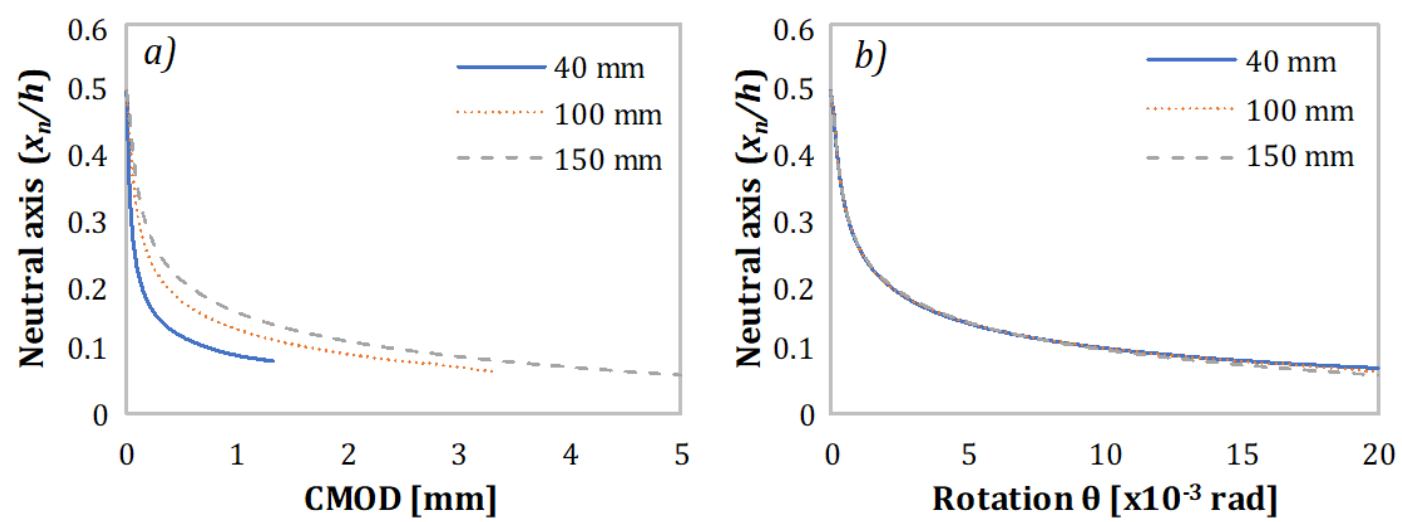

Figure 13. Neutral axis depth according to a) CMOD and b) rotation.

446 The dependence on the size of the element is greater for FCO given that the strain for a

447 given CMOD is higher in smaller specimens, shifting the neutral axis upwards the

448 section. The slight variation of $x_{n} / h$ vs. rotation with the specimen size basically lies in

449 the different shape of the constitutive law. In this case, a given rotation entails the same

450 strain, but the stress at the constitutive law associated with that strain may be different

451 depending on the size of the specimen.

452 The influence of the fibre content on the sectional stress distribution and the neutral axis

453 at the mid-span cross-section of $150 \mathrm{~mm}$ beams of the four mixes on a CMOD of

$4540.5 \mathrm{~mm}$ and a rotation $\theta=0.002 \mathrm{rad}$ is shown in Fig. 14. 

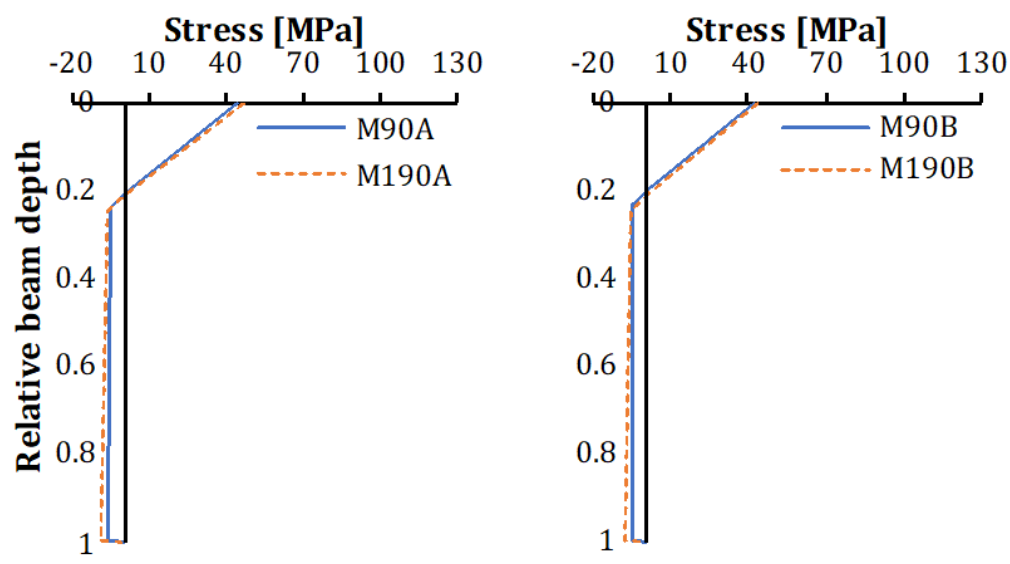

Figure 14. Neutral axis depth according to the content of fibres.

457 Notice that for this specific case of study, insignificant differences may be observed in $x_{n} / h$ when comparing the results according to the content of fibres. This is in line with 459 the results of previous studies [53], which show that the position of the neutral axis is 460 barely influenced by the content of fibres when the volume of fibres in the concrete mix 461 exceeds a volume of $1.0 \%$. However, these results may not be applicable to other cases 462 given that the position of the neutral axis does not only depend on the type and content 463 of fibres, but also on the compressive strength and the resulting equilibrium of forces at 464 the sectional analysis.

465 According to this experience, the contents of fibres below 1.0\% would lead to 466 decreasing $x_{n} / h$. A comparison of the content of fibres throughout further rotations is 467 shown in Fig. 15, showing the scarce differences in $x_{n} / h$ attributed to the content of 468 fibres. 

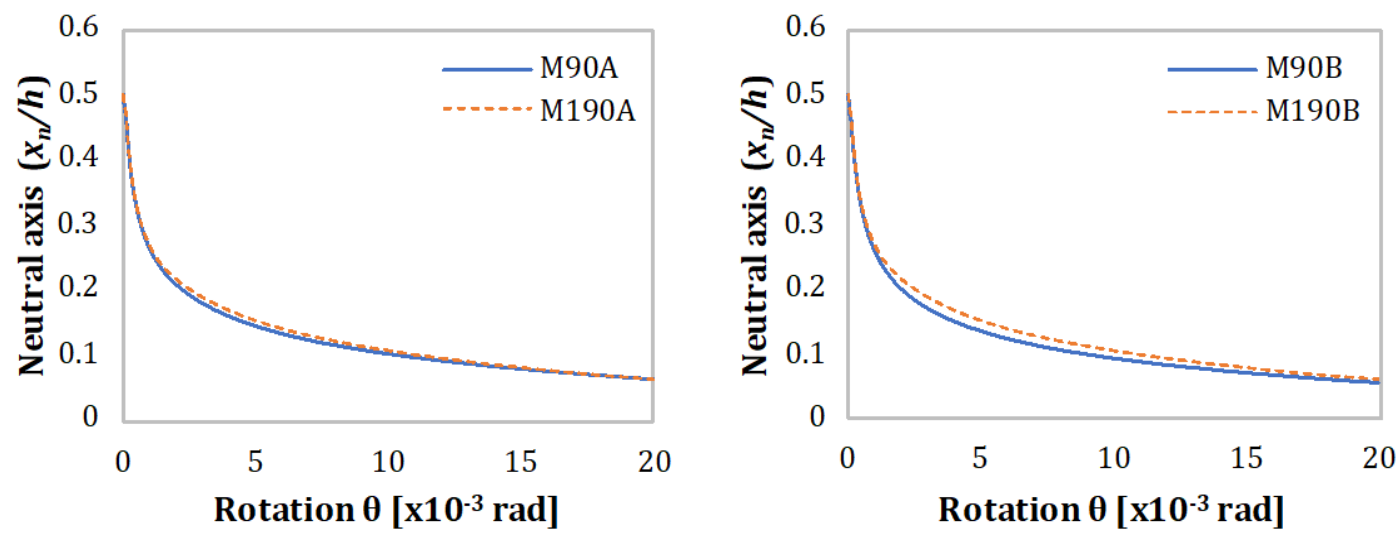

Figure 15. Extended neutral axis depth-rotation according to the content of fibres.

\section{CONCLUSIONS}

472 This study confirms the influence of the dimension of the specimens on the flexural

473 strength and proposes an alternative approach to determine the parameters of the constitutive law for FRC based on the specifications of the MC2010 to analyse and predict the behaviour of small elements. The conclusions drawn from this study state as follows:

- The results show that size effect is significantly influenced by the effect of the orientation and content of fibres. The specimens of mixes blended with $190 \mathrm{~kg} / \mathrm{m}^{3}$ of

479 fibres presented greater differences in terms of performance if compared to samples 480 of mixes with $90 \mathrm{~kg} / \mathrm{m}^{3}$ of fibres.

- Using the rotation as a reference parameter (ECO) instead of the CMOD (FCO) to define the parameters of the constitutive tensile laws leads to an improved numerical fitting of the experimental results of small elements and reduces the specimen size dependence despite ECO providing a smaller crack opening fraction than FCO. 
485 Strains and crack openings are comparatively larger in small specimens than in

486 standard ones when calculated according to FCO, whereas ECO provides

487 proportional CMODs to the size of the specimen and constant strains.

488

489

490

491

492

493

494

495

496

497

498

499

500

501

502

- Reducing the size of the element may present advantages in terms of representativeness for slender structures or elements produced with high strength concrete that allow reducing cross-section dimensions and are subjected to a greater influence of the fibres due to preferential orientations.

- Quality control procedures can be simplified, given that the reduction of the dimensions of the samples leads to lighter and more manageable specimens. Three 100x100x400 mm specimens represent nearly $30 \%$ of the total volume of concrete used to produce three $150 \times 150 \times 600 \mathrm{~mm}$ samples, thus also reducing material costs, especially in works with large concrete production.

- Testing procedures for smaller specimens may remain constant with regard to tests conducted on standard specimens. In any case, only equivalent crack openings need to be measured. However, further work should be conducted to determine the influence of the test rate on the data acquisition and the test stability, especially after the strength drop at first crack.

\section{Acknowledgements}

The first author acknowledges the Spanish Ministry of Science, Innovation and

Universities for the FPU13/04864 grant. The authors also want to express their gratitude 
to the Spanish Ministry of Economy, Industry and Competitiveness for the financial support through the SAES project (BIA2016-78742-C2-1-R).

\section{Data availability}

The raw/processed data required to reproduce these findings cannot be shared at this time as the data also forms part of an ongoing study.

\section{REFERENCES}

511 [1] Mahmud GH, Yang Z, Hassan AMT. Experimental and numerical studies of size

[2] Awinda K, Chen J, Barnett SJ. Investigating geometrical size effect on the flexural strength of the ultra high performance fibre reinforced concrete using the cohesive crack model. Constr Build Mater 2016;105:123-31.

[3] Yoo D-Y, Banthia N, Kang S-T, Yoon Y-S. Size effect in ultra-high-performance concrete beams. Eng Fract Mech 2016;157:86-106.

[4] Yoo D-Y, Banthia N, Yang J-M, Yoon Y-S. Size effect in normal- and highstrength amorphous metallic and steel fiber reinforced concrete beams. Constr Build Mater 2016;121:676-85.

[5] Hoover CG, Bažant ZP. Cohesive crack, size effect, crack band and work-offracture models compared to comprehensive concrete fracture tests. Int J Fract 2014;187:133-43.

[6] RILEM TC 162-TDF. Final recommendation of RILEM TC 162-TDF: Test and 
design methods for steel fibre reinforced concrete sigma-epsilon-design method. Mater Struct 2003;36:560-7.

[7] Blanco A, Pujadas P, de la Fuente A, Cavalaro S, Aguado A. Application of constitutive models in European codes to RC-FRC. Constr Build Mater 2013;40:246-59.

[8] International Federation for Structural Concrete. fib Model Code for Concrete Structures 2010. 2010.

[9] Blanco A, Cavalaro S, de la Fuente A, Grünewald S, Blom CBM, Walraven JC. Application of FRC constitutive models to modelling of slabs. Mater Struct $2015 ; 48: 2943-59$.

[10] Blanco A, Pujadas P, de la Fuente A, Cavalaro SHP, Aguado A. Assessment of the fibre orientation factor in SFRC slabs. Compos Part B Eng 2015;68:343-54.

[11] Blanco A, Pujadas P, De la Fuente A, Cavalaro SHP, Aguado A. Influence of the Type of Fiber on the Structural Response and Design of FRC Slabs. J Struct Eng 2016;142:04016054.

[12] Bastien-Masse M, Denarié E, Brühwiler E. Effect of fiber orientation on the inplane tensile response of UHPFRC reinforcement layers. Cem Concr Compos 2016;67:111-25.

[13] Alberti MG, Enfedaque A, Gálvez JC. On the prediction of the orientation factor and fibre distribution of steel and macro-synthetic fibres for fibre-reinforced concrete. Cem Concr Compos 2017;77:29-48.

[14] AFGC. Ultra high performance fibre-reinforced concrete. Recommendations. 
Association Française de Génie Civil; 2013.

549

[15] CEN. EN 14651:2007. Test method for metallic fibre concrete. Measuring the flexural tensile strength (limit of proportionality (LOP), residual). 2007.

[16] de Montaignac R, Massicotte B, Charron J-P. Design of SFRC structural elements: flexural behaviour prediction. Mater Struct 2012;45:623-36.

[17] di Prisco M, Colombo M, Dozio D. Fibre-reinforced concrete in fib Model Code 2010: principles, models and test validation. Struct Concr 2013;14:342-61.

[18] Di Carlo F, Meda A, Rinaldi Z. Design procedure for precast fibre-reinforced concrete segments in tunnel lining construction. Struct Concr 2016;17:747-59.

[19] Giaccio G, Tobes JM, Zerbino R. Use of small beams to obtain design parameters of fibre reinforced concrete. Cem Concr Compos 2008;30:297-306.

[20] de la Fuente A, Escariz RC, de Figueiredo AD, Molins C, Aguado A. A new design method for steel fibre reinforced concrete pipes. Constr Build Mater 2012;30:54755.

[21] de la Fuente A, Aguado A, Molins C, Armengou J. Numerical model for the analysis up to failure of precast concrete sections. Comput Struct 2012;106107:105-14.

[22] Liao L, de la Fuente A, Cavalaro S, Aguado A. Design procedure and experimental study on fibre reinforced concrete segmental rings for vertical shafts. Mater Des 2016;92:590-601.

[23] Mobasher B, Bakhshi M, Barsby C. Backcalculation of residual tensile strength of regular and high performance fiber reinforced concrete from flexural tests. Constr 
571

[24] Mobasher B, Yao Y, Soranakom C. Analytical solutions for flexural design of hybrid steel fiber reinforced concrete beams. Eng Struct 2015;100:164-77.

[25] Yoo D-Y, Yoon Y-S. Structural performance of ultra-high-performance concrete beams with different steel fibers. Eng Struct 2015;102:409-23.

[26] López JÁ, Serna P, Navarro-Gregori J, Camacho E. An inverse analysis method based on deflection to curvature transformation to determine the tensile properties of UHPFRC. Mater Struct 2015;48:3703-18.

[27] López JÁ, Serna P, Navarro-Gregori J, Coll H. A simplified five-point inverse analysis method to determine the tensile properties of UHPFRC from unnotched four-point bending tests. Compos Part B Eng 2016;91:189-204.

[28] Yoo D-Y, Yoon Y-S. A Review on Structural Behavior, Design, and Application of Ultra-High-Performance Fiber-Reinforced Concrete. Int J Concr Struct Mater 2016;10:125-42.

[29] Wille K, El-Tawil S, Naaman AE. Properties of strain hardening ultra high performance fiber reinforced concrete (UHP-FRC) under direct tensile loading. Cem Concr Compos 2014;48:53-66.

[30] Ghafari E, Costa H, Júlio E, Portugal A, Durães L. The effect of nanosilica addition on flowability, strength and transport properties of ultra high performance concrete. Mater Des 2014;59:1-9.

[31] CEN. EN 12390-3. Testing hardened concrete. Part 3: Compressive strength of test specimens. 2009. 
[32] CEN. EN 12390-13:2014. Testing hardened concrete - Part 13: Determination of secant modulus of elasticity in compression 2014.

[33] Hoover CG, P. Bažant Z, Vorel J, Wendner R, Hubler MH. Comprehensive concrete fracture tests: Description and results. Eng Fract Mech 2013;114:92-103.

[34] Trivedi N, Singh RK, Chattopadhyay J. Investigation on fracture parameters of concrete through optical crack profile and size effect studies. Eng Fract Mech 2015;147:119-39.

[35] Kirane K, Bažant ZP. Size effect in Paris law and fatigue lifetimes for quasibrittle materials: Modified theory, experiments and micro-modeling. Int $\mathrm{J}$ Fatigue 2016;83:209-20.

[36] Sorelli LG, Meda A, Plizzari GA. Bending and Uniaxial Tensile Tests on Concrete Reinforced with Hybrid Steel Fibers. J Mater Civ Eng 2005;17:519-27.

[37] Soutsos MN, Le TT, Lampropoulos AP. Flexural performance of fibre reinforced concrete made with steel and synthetic fibres. Constr Build Mater 2012;36:70410.

[38] Yoo D-Y, Shin H-O, Yang J-M, Yoon Y-S. Material and bond properties of ultra high performance fiber reinforced concrete with micro steel fibers. Compos Part B Eng 2014;58:122-33.

[39] Pająk M, Ponikiewski T. Flexural behavior of self-compacting concrete reinforced with different types of steel fibers. Constr Build Mater 2013;47:397-408.

[40] Yoo D-Y, Kim S, Park G-J, Park J-J, Kim S-W. Effects of fiber shape, aspect ratio, and volume fraction on flexural behavior of ultra-high-performance fiber- 
reinforced cement composites. Compos Struct 2017;174:375-88.

615 [41] Buratti N, Mazzotti C, Savoia M. Post-cracking behaviour of steel and macrosynthetic fibre-reinforced concretes. Constr Build Mater 2011;25:2713-22.

[42] Alberti MG, Enfedaque A, Gálvez JC, Agrawal V. Reliability of polyolefin fibre reinforced concrete beyond laboratory sizes and construction procedures. Compos Struct 2016;140:506-24.

[43] Lameiras R, Barros JAO, Azenha M. Influence of casting condition on the

[46] Yoo D-Y, Banthia N, Kang S-T, Yoon Y-S. Size effect in ultra-high-performance concrete beams. Eng Fract Mech 2016;157:86-106.

[47] Wu Z, Shi C, He W, Wu L. Effects of steel fiber content and shape on mechanical properties of ultra high performance concrete. Constr Build Mater 2016;103:8-14.

[48] Zhou B, Uchida Y. Influence of flowability, casting time and formwork geometry on fiber orientation and mechanical properties of UHPFRC. Cem Concr Res 2017;95:164-77. 
636 [49] Yu R, Spiesz P, Brouwers HJH. Mix design and properties assessment of Ultra637 High Performance Fibre Reinforced Concrete (UHPFRC). Cem Concr Res 2014;56:29-39.

639 [50] Söylev TA, Özturan T. Durability, physical and mechanical properties of fiberreinforced concretes at low-volume fraction. Constr Build Mater 2014;73:67-75.

641 [51] Zerbino R, Tobes JM, Bossio ME, Giaccio G. On the orientation of fibres in 642 structural members fabricated with self compacting fibre reinforced concrete. Cem Concr Compos 2012;34:191-200.

644

[52] Lawler JS, Zampini D, Shah SP. Microfiber and Macrofiber Hybrid FiberReinforced Concrete. J Mater Civ Eng 2005;17:595-604.

[53] Yoo D-Y, Yoon Y-S. A Review on Structural Behavior, Design, and Application of Ultra-High-Performance Fiber-Reinforced Concrete. Int J Concr Struct Mater 2016;10:125-42. 